\title{
Chitosan as an Adjuvant to Improve Isopyrazam Azoxystrobin against Leaf Spot Disease of Kiwifruit and Enhance Its Photosynthesis, Quality, and Amino Acids
}

\author{
Qiuping Wang ${ }^{1,2}$, Haitao $\mathrm{Li}^{1}$, Yang Lei ${ }^{1}$, Yue Su ${ }^{1, *}$ and Youhua Long ${ }^{2, *}$ \\ 1 Department of Food and Medicine, Guizhou Vocational College of Agriculture, Qingzhen 551400, China; \\ qpwang518@aliyun.com (Q.W.); lisea02@126.com (H.L.); gznzyylei@126.com (Y.L.) \\ 2 Research Center for Engineering Technology of Kiwifruit, Institute of Crop Protection, \\ Teaching Experimental Farm, College of Agriculture, Guizhou University, Guiyang 550025, China \\ * Correspondence: suyue09136@163.com (Y.S.); yhlong3@gzu.edu.cn (Y.L.)
}

\section{check for} updates

Citation: Wang, Q.; Li, H.; Lei, Y.; Su, Y.; Long, Y. Chitosan as an Adjuvant to Improve Isopyrazam Azoxystrobin against Leaf Spot Disease of Kiwifruit and Enhance Its Photosynthesis, Quality, and Amino Acids. Agriculture 2022, 12, 373. https:// doi.org/10.3390/agriculture12030373

Academic Editors: Eugenio Llorens, Begonya Vicedo, Loredana Scalschi and Carlos Agustí-Brisach

Received: 27 December 2021

Accepted: 4 March 2022

Published: 7 March 2022

Publisher's Note: MDPI stays neutral with regard to jurisdictional claims in published maps and institutional affiliations.

Copyright: (c) 2022 by the authors. Licensee MDPI, Basel, Switzerland. This article is an open access article distributed under the terms and conditions of the Creative Commons Attribution (CC BY) license (https:// creativecommons.org/licenses/by/ $4.0 /)$.

\begin{abstract}
Leaf spot disease caused by Lasiodiplodia theobromae is one of the most serious fungal diseases of kiwifruit production. In this work, the co-application of isopyrazam-azoxystrobin and chitosan against leaf spot disease in kiwifruit and its effects on disease resistance, photosynthesis, yield, quality, and amino acids of kiwifruit were investigated. The results show that isopyrazam-azoxystrobin exhibited a superior bioactivity against $L$. theobromae with an $\mathrm{EC}_{50}$ value of $0.1826 \mathrm{mg} \mathrm{kg}^{-1}$. The foliar application of chitosan could effectively enhance isopyrazam azoxystrobin against leaf spot disease with a field control efficacy of $86.83 \%$ by spraying $29 \%$ isopyrazam azoxystrobin suspension concentrate (SC) 1500 time + chitosan 100-time liquid, which was significantly $(p<0.05)$ higher than $78.70 \%$ of $29 \%$ isopyrazam azoxystrobin SC 1000-time liquid. The co-application of isopyrazam azoxystrobin and chitosan effectively enhanced soluble protein, resistance enzymes' activity in kiwifruit leaves, and reduced their malonaldehyde (MDA), as well as reliably improved their photosynthetic characteristics. Simultaneously, their co-application was more effective in promoting growth, quality, and amino acids of kiwifruit fruits compared to isopyrazam-azoxystrobin or chitosan alone. This study highlights that the co-application of isopyrazam-azoxystrobin and chitosan can be used as a green, safe, and efficient approach for controlling leaf spot disease of kiwifruit and reducing the application of chemical fungicides.
\end{abstract}

Keywords: chitosan; growth and quality; isopyrazam·azoxystrobin; kiwifruit; leaf spot disease; resistance

\section{Introduction}

Kiwifruit (Actinidia chinensis), an edible and medicinal third-generation fruit rich in vitamin $C$, essential amino acids for humans and various minerals, has high nutritional, medicinal, and economical values [1-3]. Recently, the planting area and annual output of the kiwifruit industry in China have reached $243,000 \mathrm{hm}^{2}$ and 2.5 million tons by 2020, respectively [2,3]. As a momentous poverty-reducing and revitalizing rural industry, the kiwifruit industry in the Guizhou Province of Southwest China has developed rapidly, and its planting area reached over $40,000 \mathrm{hm}^{2}$. Nevertheless, leaf spot disease caused by fungal pathogens such as Lasiodiplodia theobromae, Altemaria sp., Corynespora cassiicola, Pseudocercospora actinidiae deighton, Phomopsis sp., and Glomerella cingulata occur frequently, and seriously affect the quality and yield of kiwifruit [4-8]. Shi et al. [8] reported that leaf spot disease caused by L. theobromae is one of the most serious fungal diseases of the kiwifruit production area in Guizhou Province; the initial stage is in late June and the peak stage is from July to August, and its spots are round or irregularly shaped brown necrosis. It seriously affects the growth and photosynthesis of kiwifruit plants, resulting in a reduction in kiwifruit yield and quality, as well as major economic losses. Consequently, 
there is an urgent need to develop a green, safe, and effective control strategy against leaf spot disease of kiwifruit.

Currently, chemical fungicides with high efficiency and low toxicity are still the most effective and frequent measures for controlling plant diseases. However, it is generally believed that chemical fungicide residuals are potential risks to the environment, wildlife, and human beings [9]. Additionally, chemical fungicides can easily lead to fungicide resistance of pathogens [10,11]. As a consequence, the reducing application of chemical fungicides has a great practical significance for the sustainable development of the kiwifruit industry. Compared to chemical fungicides, natural products are mild and basically harmless, which has been suggested as a reason for natural products being preferred by consumers and farmers, and their increasingly popular use in agriculture [12,13]. Meanwhile, some studies also found fungicides were inefficient for controlling plant diseases and even increased plant pathogens $[14,15]$. In that case, whether natural products can be used as an adjuvant of chemical fungicides to more effectively control plant diseases, reduce the application of chemical fungicides, decrease the detrimental effects of fungicides on beneficial microbiota, and delay the resistance of pathogens to chemical fungicides is worth further exploration and application.

Chitosan, a natural macromolecule compound for sustainable agriculture, has many prominent advantages including antimicrobial, nontoxicity, antioxidation, renewability, biocompatibility, etc. [16-18]. Many studies have shown that chitosan can be used as a resistance inductor and bio-fungicide to induce the control of plant diseases and as an enhancer to promote plant growth [16-21]. For instance, Li et al. [22] reported that the foliar application of $1.0 \sim 1.5 \%$ chitosan could effectively control powdery mildew of Rosa roxburghii and notably induce the systemic disease resistance of $R$. roxburghii, as well as reliably enhance its photosynthesis, growth, yield, and quality. Chitosan can induce morphological changes and structural alterations in fungal cells, and also enhance resistant enzymes, phytoalexins, callose formation, and lignification [18,23,24]. In our previous study, chitosan could enhance tetramycin against soft rot of kiwifruit and promote tetramycin's improvement for the yield, quality, and aroma of kiwifruit fruits [25]. Accordingly, it is worth further study whether chitosan can enhance chemical fungicides against leaf spot disease of kiwifruit and reduce their application.

In this study, the high bioactivity isopyrazam-azoxystrobin against $L$. theobromae was first obtained. Subsequently, the field control efficacy of the co-application of isopyrazam. azoxystrobin and chitosan on leaf spot disease of kiwifruit was evaluated. Homoplastically, the effects of the co-application of isopyrazam azoxystrobin and chitosan on the disease resistance, growth, yield, quality, and amino acids of kiwifruit were also investigated. This work may provide a green, safe, and efficient strategy for controlling leaf spot disease of kiwifruit and reducing the application of chemical fungicides.

\section{Materials and Methods}

\subsection{Pathogen, Fungicide and Culture Medium}

Lasiodiplodia theobromae with high pathogenicity was isolated from the 'Guichang' kiwifruit leaves in an orchard at Xifeng County, Guizhou Province, China, and was preserved in the Research Center for Engineering Technology of Kiwifruit, Guizhou University (Guiyang, China). Moreover, 29\% isopyrazam -azoxystrobin suspension concentrate (SC), 50\% cyprodinil water dispersible granule (WDG), and 10\% difenoconazole WDG were purchased from Syngenta Crop Protection Co. Ltd. (Suzhou, China); $0.3 \%$ tetramycin aqueous solutions (AS) and 5\% hexaconazole-tetramycin micro-emulsion (ME) were purchased from Microke Biological Engineering Co. Ltd. (Liaoning, China); 48\% oxime-tebuconazole SC was obtained from Ruilian Chemical Co., Ltd. (Shanghai, China); 0.3\% eugenol soluble liquid (SL) was purchased from Yada Chemical Co. Ltd. (Baoding, China); 75\% pentazole-azoxystrobin WDG was purchased from Suli Chemical Co. Ltd. (Jiangyin, China); $\%$ oligosaccharins AS was purchased from Guida Technology Industry Co., Ltd. (Anshun, China). Chitosan (Deacetylation $\geq 90.00 \%$ ) was purchased from Huarun bioengi- 
neering Co. Ltd. (Zhenzhou, China). Potato dextrose agar (PDA, g L ${ }^{-1}$ ): $200 \mathrm{~g}$ potato, $20 \mathrm{~g}$ dextrose, $15 \mathrm{~g}$ agar, and $1 \mathrm{~L}$ distilled water, $\mathrm{pH}$ neutral. PDA culture medium was sterilized at $121^{\circ} \mathrm{C}$ for $30 \mathrm{~min}$.

\subsection{Screening Test of Fungicides In Vitro}

The toxicities of fungicides against Lasiodiplodia theobromae were determined using the mycelium growth rate method as described by Wang et al. [3]. The tested solutions of different fungicides at five gradient concentrations were prepared with sterile water. One milliliter of tested solution of fungicide and $9 \mathrm{~mL}$ fresh PDA liquid $\left(45 \sim 55^{\circ} \mathrm{C}\right)$ were mixed uniformly, and the control was sterile water. Then, the mixed fungicide-PDA liquid was fed in Petri dishes with a $90 \mathrm{~mm}$ diameter and allowed to solidify. Subsequently, a pathogen disc $(5 \mathrm{~mm})$ was cut from a 7-days-old pathogen PDA plate and was placed in the solidified PDA center with the mycelium side down, and three replicates. The diameters of $L$. theobromae growth in the treated plate were measured by the cross-crossing method after incubation at $28{ }^{\circ} \mathrm{C}$ for 2 days. The growth inhibition of $L$. theobromae was calculated as Equation (1):

Inhibition rate $(\%)=100 \times[($ Mycelium diameter in control dish - Mycelium diameter in treatment dish)/(Mycelium diameter in control dish - 5)]

The $\mathrm{EC}_{50}$ (effective concentration of $50 \%$ inhibition rate) values of different fungicides against $L$. theobromae were calculated by SPSS 18.0 software.

\subsection{Field Control Experiments of Leaf Spot Disease of Kiwifruit}

The field experiments were carried out in 2021 in an orchard of kiwifruit with a 5-year-old 'Guichang' cultivar in Zhongkang Agricultural Science and Technology Co. Ltd., Shidong Town, Xifeng country, Guizhou Province, China $\left(27^{\circ} 04^{\prime}, 106^{\circ} 55^{\prime}\right)$. The plant spacing of kiwifruit was $3.00 \mathrm{~m} \times 3.00 \mathrm{~m}$, and female plants account for $8 / 9$ of the total plants. The annual rainfall, temperature, and mean altitude of the kiwifruit orchard were about $1203 \mathrm{~mm}, 12.5^{\circ} \mathrm{C}$, and $1250 \mathrm{~m}$, respectively. The loam soils $(0 \sim 60 \mathrm{~cm}$ in deep) had $41.93 \mathrm{~g} \mathrm{~kg}^{-1}$ of organic matter, $1.23 \mathrm{~g} \mathrm{~kg}^{-1}$ of total nitrogen, $96.85 \mathrm{mg} \mathrm{kg}^{-1}$ of alkali-hydrolyzable nitrogen, $15.76 \mathrm{mg} \mathrm{kg}^{-1}$ of available phosphorus, and $1.35 \mathrm{mg} \mathrm{kg}^{-1}$ of available potassium, 6.45 of $\mathrm{pH}$ value.

The control experiment of leaf spot disease in kiwifruit was carried out using the foliar spray method. The experimental treatments included $29 \%$ isopyrazam azoxystrobin SC 1500 time + chitosan 100-time dilution liquid, 29\% isopyrazam azoxystrobin SC 1000-time dilution liquid, chitosan 100-time dilution liquid, and clear water (Control). Three replicates were set for each treatment. Twelve plots were arranged randomly, each plot had nine trees, and five trees on the diagonal were used for measure. Leaf spot disease mainly began to damage kiwifruit leaves in late June every year and reached the peak in August. Thus, about $1.00 \mathrm{~L}$ of fungicide dilution liquid was sprayed on kiwifruit plants (including leaves, stems, and fruits) between 25 June and 25 July in 2021 by a 3WBD-16B electrostatic backpack sprayer (Jianeng plant protection machinery factory, Taizhou, China), respectively. No rainfall was found after $3 \sim 4$ days of the spray experiment.

\subsection{Investigation of Control Effect of Leaf Spot Disease}

The control effect of tested fungicides for leaf spot disease in kiwifruit was investigated on 30 August in 2021 according to Zhao et al. [4] with slight modifications. Twenty leaves from the east, west, south, north, and middle parts of each tested tree were used for investigation. The disease index and control effect of tested fungicides for leaf spot disease in kiwifruit were calculated according to Equations (2) and (3), respectively. The incidence degree: $0=$ no incidence, $1=$ the area of diseased spots accounted for less than $10 \%$ of the whole leaf area, $3=$ the area of diseased spots accounted for $11 \sim 25 \%$ of the whole leaf area, $5=$ the area of diseased spots accounted for $26 \sim 40 \%$ of the whole leaf area, $7=$ the area of 
diseased spots accounted for $41 \sim 65 \%$ of the whole leaf area, $9=$ the area of diseased spots accounted for more than $65 \%$ of the whole leaf area.

Disease index $=100 \times \sum$ (Disease grade value $\times$ Number of leaves within each grade) $/($ Total number of leaves $\times$ the highest grade)

Control effect $(\%)=100 \times(1$-Disease index of treatment/Disease index of control $)$

2.5. Determination of Soluble Protein, Malonaldehyde (MDA), Resistance Enzyme Activities and Photosynthetic Characteristics of Kiwifruit Leaves

The soluble protein, MDA, resistance enzyme activities, and photosynthetic characteristics of kiwifruit leaves were also determined on 25 August in 2021. The soluble protein, MDA, CAT activity, POD activity, PPO activity, and SOD activity of kiwifruit leaves were checked according to Zhang et al. [26,27]. The chlorophyll content of kiwifruit leaves was determined by a UV-5800PC spectrophotometer at $645 \mathrm{~nm}$ and $663 \mathrm{~nm}$ with acetoneethanol $(v / v, 2: 1)$ extraction. The photosynthetic rate $(\mathrm{Pn})$ and transpiration rate $(\mathrm{Tr})$ of kiwifruit leaves were monitored by a portable LI-6400XT photosynthesis measurement system (LI-COR Inc., Lincoln, NE, USA) at 8:00-10:00 a.m. on 25 August in 2021. Water use efficiency (WUE) of kiwifruit was Pn/Tr.

\subsection{Determination of Yield, Quality and Amino Acids of Kiwifruit}

Two kiwifruit fruits from the east, west, south, north, and middle parts of each tested tree were collected on 25 September 2021. The growth parameters such as the longitudinal diameter, transverse diameter, lateral diameter, fruit shape index, single fruit volume, and single fruit weight of kiwifruit fruits were determined as described by Zhang et al. [26,27]. Moreover, the fruit quality of kiwifruit, including vitamin C, soluble sugar, soluble solid, dry matter, and titratable acidity were determined according to Wang et al. [25]. When kiwifruit fruits reached an edible state, their 17 hydrolyzed amino acids were determined by an HPLC system (ThermoFisher U3000, Waltham, MA, USA) according to Zhang et al. [28]. Simultaneously, sweet, flavor, bitter, aromatic, essential, nonessential, and total amino acids were calculated based on the contents of 17 hydrolyzed amino acids. Sweet amino acids were equal to the sum of serine, glycine, histidine, threonine, alanine, and proline; flavor amino acids were equal to the sum of aspartic, glutamate, and lysine; bitter amino acids were equal to the sum of arginine, valine, methionine, isoleucine, and leucine; aromatic amino acids were equal to the sum of cystine, tyrosine, and phenylalanine. Essential amino acids were equal to the sum of threonine, valine, methionine, isoleucine, leucine, phenylalanine, and lysine; nonessential amino acids were equal to the sum of aspartic, glutamate, cystine, serine, glycine, histidine, arginine, alanine, and tyrosine; total amino acids were equal to the sum of 17 hydrolyzed amino acids.

\subsection{Statistical Analyses}

Values indicate the mean \pm standard deviation (SD) of three replicates. Data were carried on SPSS 18.0 (SPSS Inc., Chicago, IL, USA). A one-way analysis of variance (ANOVA) was determined for significant differences. Origin 10.0 was used for drawing the charts.

\section{Results}

\subsection{Toxicity of Different Fungicides against Lasiodiplodia Theobromae}

The toxicities of nine fungicides and chitosan against $L$. theobromae are shown in Table 1 . As can be seen, 29\% isopyrazam azoxystrobin SC showed excellent toxic activity against L. theobromae with an $\mathrm{EC}_{50}$ value of $0.1826 \mathrm{mg} \mathrm{kg}^{-1}$, which was $12.98,19.55,19.88,19.93$, $151.81,211.72,346.88,889.98$, and 2658.32 -fold higher compared to $0.3 \%$ Tetramycin AS, $48 \%$ oxime tebuconazole SC, 50\% cyprodinil WDG, $0.3 \%$ eugenol SL, $10 \%$ difenoconazole WDG, $5 \%$ hexaconazole tetramycin ME, $75 \%$ pentazole azoxystrobinWDG, $2 \%$ oligosaccharins AS, and chitosan, respectively. However, chitosan possessed a relatively inferior toxicity against $L$. theobromae with an $\mathrm{EC}_{50}$ value of $485.4125 \mathrm{mg} \mathrm{kg}^{-1}$. The results indicate that $29 \%$ 
isopyrazam·azoxystrobin SC had a notable potential to control leaf spot disease of kiwifruit in the field.

Table 1. The toxicity of ten fungicides against Lasiodiplodia theobromae.

\begin{tabular}{|c|c|c|c|}
\hline Fungicides & Regression Equation & $\mathrm{EC}_{50}\left(\mathrm{mg} \mathrm{kg}^{-1}\right)$ & Determination Coefficient $\left(R^{2}\right)$ \\
\hline $29 \%$ Isopyrazam $\cdot$ Azoxystrobin SC & $y=5.2485+0.3365 x$ & 0.18 & 0.9933 \\
\hline $0.3 \%$ Tetramycin AS & $y=4.5323+1.2463 x$ & 2.37 & 0.9840 \\
\hline $48 \%$ Oxime Tebuconazole SC & $y=4.6315+0.6662 x$ & 3.57 & 0.9769 \\
\hline 50\% Cyprodinil WDG & $y=4.6730+0.5843 x$ & 3.63 & 0.9925 \\
\hline $0.3 \%$ Eugenol SL & $y=4.0371+1.7167 x$ & 3.64 & 0.9911 \\
\hline 10\% Difenoconazole WDG & $y=4.2910+0.4914 x$ & 27.72 & 0.9811 \\
\hline 5\% Hexaconazole $\cdot$ Tetramycin ME & $y=4.0744+0.5832 x$ & 38.66 & 0.9841 \\
\hline 75\% Pentazole·AzoxystrobinWDG & $y=4.1627+0.4647 x$ & 63.34 & 0.9533 \\
\hline $2 \%$ Oligosaccharins AS & $y=2.4191+1.1674 x$ & 162.51 & 0.9989 \\
\hline Chitosan & $y=5.2904+0.9250 x$ & 485.41 & 0.9865 \\
\hline
\end{tabular}

$y$ and $x$ indicate the inhibition rate and fungicide concentration, respectively.

3.2. Field Control Effect of Isopyrazam.Azoxystrobin and Chitosan against Leaf Spot Disease of Kiwifruit

The field control effects of isopyrazam azoxystrobin + chitosan, isopyrazam ·azoxystrobin, and chitosan against leaf spot disease of kiwifruit are shown in Table 2. Isopyrazam azoxystrobin + chitosan, isopyrazam·azoxystrobin, and chitosan significantly $(p<0.01)$ decreased the disease index of leaf spot disease of kiwifruit, isopyrazam azoxystrobin + chitosan, which was the most effective, and no significant difference from isopyrazam-azoxystrobin was observed. The control effect of isopyrazam·azoxystrobin 1500 time + chitosan 100-time liquid against leaf spot disease was $86.83 \%$, which was significantly $(p<0.05)$ higher than $78.70 \%$ of isopyrazam-azoxystrobin 1000-time liquid and significantly $(p<0.01)$ better than 55.33\% of chitosan 100-time liquid. These results indicate that chitosan had an outstanding induced control effect on leaf spot disease, and its mixed application with isopyrazam-azoxystrobin could significantly improve the control effect of leaf spot disease of kiwifruit and reduce the application of isopyrazam·azoxystrobin.

Table 2. The control effect of isopyrazam-azoxystrobin and chitosan against leaf spot disease of kiwifruit under field conditions.

\begin{tabular}{ccc}
\hline Treatments & Disease Index & Control Effect (\%) \\
\hline Isopyrazam·Azoxystrobin + Chitosan & $1.26 \pm 0.22^{\mathrm{cC}}$ & $86.83 \pm 2.14^{\mathrm{aA}}$ \\
Isopyrazam·Azoxystrobin & $2.04 \pm 0.23^{\mathrm{cC}}$ & $78.70 \pm 0.74^{\mathrm{bA}}$ \\
Chitosan & $4.25 \pm 0.25^{\mathrm{bB}}$ & $55.33 \pm 4.90^{\mathrm{cB}}$ \\
Control & $9.56 \pm 0.73^{\mathrm{aA}}$ &
\end{tabular}

Values indicate the mean \pm SD of three replicates. Different small and capital letters in the same column indicate significant differences at $5 \%$ level $(p<0.05)$ and $1 \%$ level $(p<0.01)$, respectively.

\subsection{Effects of Isopyrazam.Azoxystrobin and Chitosan on Soluble Protein, MDA and Resistance Enzyme Activities of Kiwifruit Leaves}

The effects of isopyrazam·azoxystrobin + chitosan, isopyrazam·azoxystrobin, and chitosan on the soluble protein, MDA, CAT, POD, PPO, and SOD activities of kiwifruit leaves are depicted in Figure 1. Compared to isopyrazam·azoxystrobin, chitosan, and control, isopyrazam azoxystrobin + chitosan significantly $(p<0.01)$ enhanced soluble protein, CAT, POD, PPO, and SOD activities of kiwifruit leaves and decreased their MDA content. Compared to the control, isopyrazam -azoxystrobin significantly $(p<0.01)$ enhanced soluble protein, POD, and SOD activities of kiwifruit leaves and significantly $(p<0.05)$ increased their CAT and PPO activities, as well as significantly $(p<0.05)$ decreased their MDA content. Compared to the control, chitosan significantly $(p<0.01)$ enhanced soluble protein, CAT, POD, and SOD activities of kiwifruit leaves and significantly $(p<0.05)$ increased their PPO activity, as well as significantly $(p<0.01)$ decreased 
their MDA content. Compared to isopyrazam-azoxystrobin, chitosan could significantly $(p<0.05)$ improve soluble protein, CAT, and SOD activities of kiwifruit leaves. These results indicate that the co-application of isopyrazam-azoxystrobin and chitosan could effectively improve the enhancing or inhibiting effects of isopyrazam-azoxystrobin or chitosan on the soluble protein, MDA, CAT, POD, PPO, and SOD activities of kiwifruit leaves, thereby enhancing the resistance of kiwifruit against leaf spot disease.
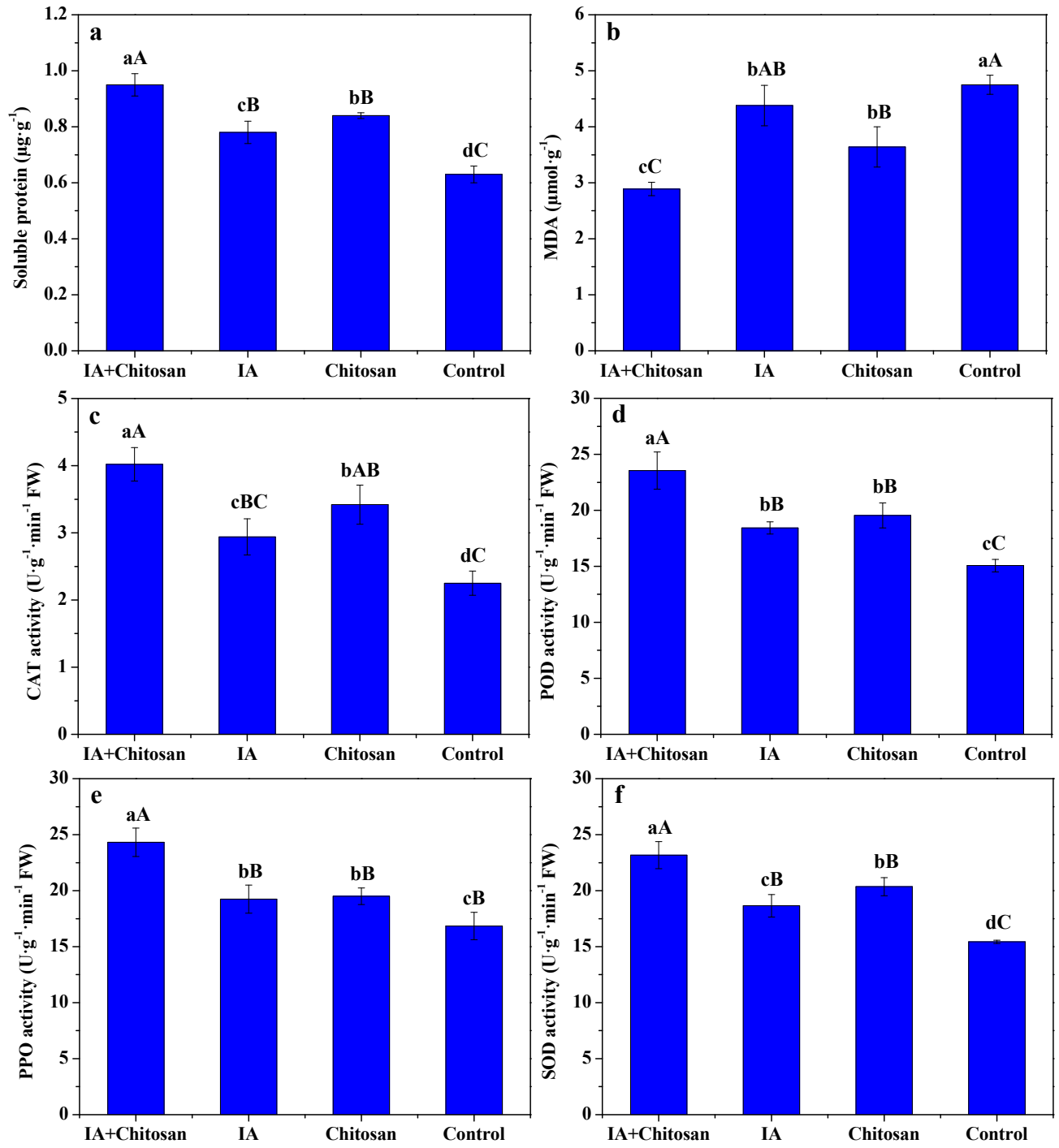

Figure 1. The effects of isopyrazam azoxystrobin and chitosan on the soluble protein (a), MDA (b), CAT activity (c), POD activity (d), PPO activity (e), and SOD activity (f) of kiwifruit leaves. Values and error bars indicate the mean and SD of three replicates, respectively. IA is the abbreviation of isopyrazam·azoxystrobin. Different small and capital letters indicate significant differences at $5 \%$ level $(p<0.05)$ and $1 \%$ level $(p<0.01)$, respectively.

\subsection{Effects of Isopyrazam.Azoxystrobin and Chitosan on Photosynthetic Characteristics of Kiwifruit Leaves}

The effects of isopyrazam·azoxystrobin + chitosan, isopyrazam·azoxystrobin, and chitosan on chlorophyll, photosynthetic rate, transpiration rate, and water use efficiency in kiwifruit leaves are shown in Figure 2. Isopyrazam·azoxystrobin + chitosan, isopyrazam azoxystrobin, and chitosan could effectively increase the chlorophyll content, photosynthetic rate, transpiration rate, and water use efficiency of kiwifruit leaves compared to the control. The chlorophyll content and transpiration rate of kiwifruit leaves treated by isopyrazam azoxystrobin + chitosan were significantly $(p<0.05)$ higher than those of 
chitosan and significantly $(p<0.01)$ higher than those of isopyrazam azoxystrobin. Additionally, the photosynthetic rate of kiwifruit leaves treated by isopyrazam azoxystrobin + chitosan was significantly $(p<0.01)$ faster than that of isopyrazam -azoxystrobin or chitosan. The photosynthetic rate of kiwifruit leaves treated with chitosan was significantly $(p<0.01)$ faster than that of isopyrazam azoxystrobin, and its transpiration rate was significantly $(p<0.05)$ faster than that of isopyrazam azoxystrobin. These results indicate that the co-application of isopyrazam azoxystrobin and chitosan effectively promoted the chlorophyll, photosynthetic rate, transpiration rate, and water use efficiency of kiwifruit, thereby enhancing its growth and development.
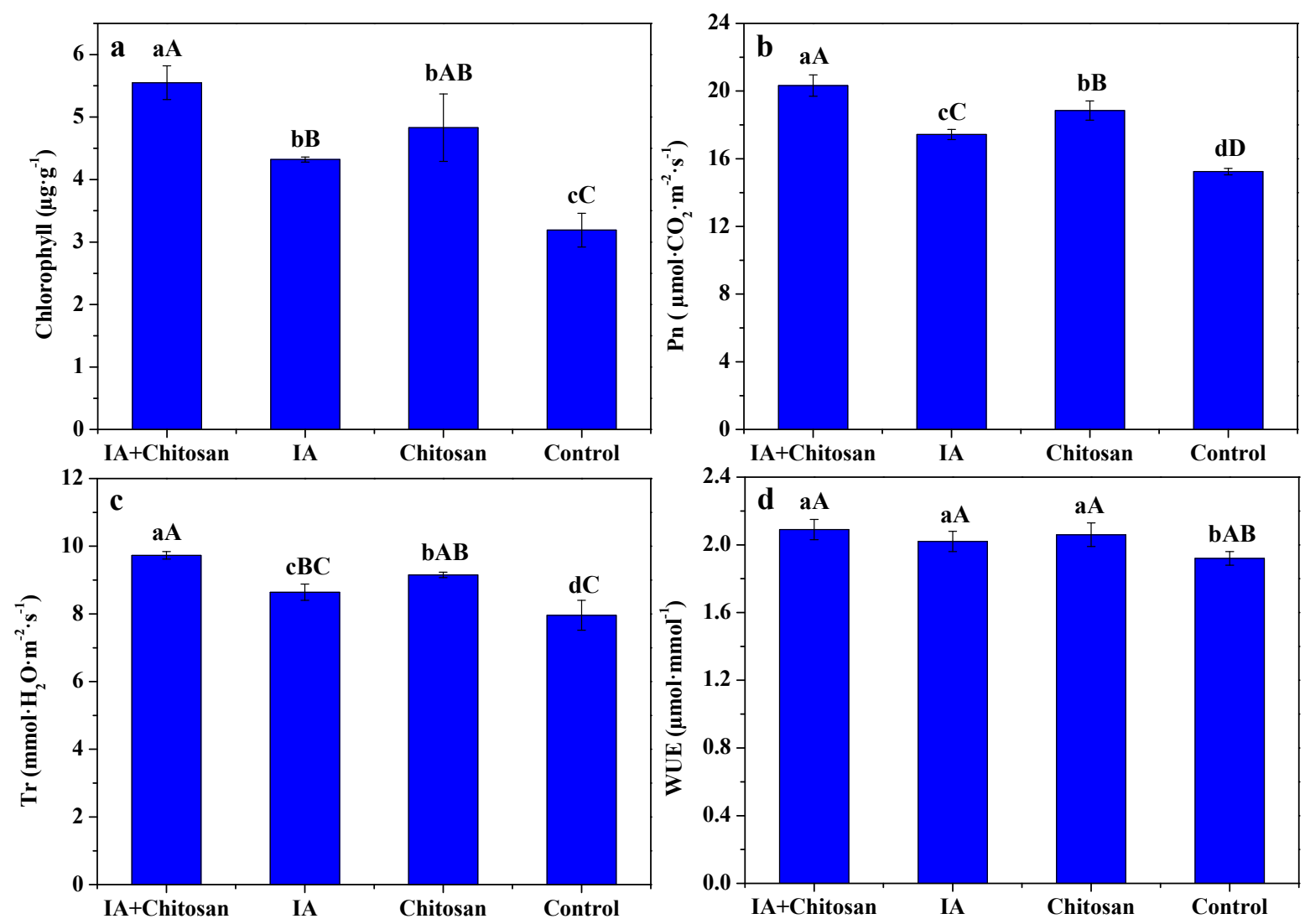

Figure 2. The effects of isopyrazam-azoxystrobin and chitosan on the chlorophyll (a), photosynthetic rate (b), transpiration rate (c), and water use efficiency (d) of kiwifruit leaves. Values and error bars indicate the mean and SD of three replicates, respectively. IA-isopyrazam -azoxystrobin. Different small and capital letters indicate significant differences at $5 \%$ level $(p<0.05)$ and $1 \%$ level $(p<0.01)$, respectively.

\subsection{Effects of Isopyrazam.Azoxystrobin and Chitosan on Growth, Quality and Amino Acids of Kiwifruit Fruits}

The effect of isopyrazam·azoxystrobin + chitosan, isopyrazam·azoxystrobin, and chitosan on kiwifruit fruit growth is displayed in Table 3. Isopyrazam·azoxystrobin + chitosan could significantly $(p<0.05)$ enhance the longitudinal diameter, transverse diameter, volume, and weight of fruits. Lateral diameter and fruit shape index of fruits showed no significant $(p<0.05)$ differences in the four treatments. At the same time, all growth parameters, including the longitudinal diameter, transverse diameter, lateral diameter, shape index, volume, and weight fruits, showed no significant $(p<0.05)$ differences in isopyrazam-azoxystrobin, chitosan, and control treatments. Moreover, the longitudinal diameter, transverse diameter, volume, and weight of fruits treated by isopyrazam azoxystrobin + chitosan were $83.33 \mathrm{~mm}, 51.32 \mathrm{~mm}, 73.56 \mathrm{~cm}^{3}$, and $102.34 \mathrm{~g}$, which effectively increased by $1.55,2.03$ or $4.62 \%, 4.16,4.22$, or $5.66 \%, 7.78,8.28$ or $12.85 \%$, 
and $11.57,13.01$, or $16.45 \%$ compared to isopyrazam-azoxystrobin, chitosan, or control treatments, respectively. These findings show that the promoted effects of fruit growth and yield formation by isopyrazam-azoxystrobin + chitosan were better than those of isopyrazam·azoxystrobin or chitosan alone.

Table 3. The effects of isopyrazam azoxystrobin and chitosan on the growth of kiwifruit fruits.

\begin{tabular}{|c|c|c|c|c|c|c|}
\hline Treatments & $\begin{array}{c}\text { Longitudinal } \\
\text { Diameter (mm) }\end{array}$ & $\begin{array}{c}\text { Transverse } \\
\text { Diameter }(\mathbf{m m})\end{array}$ & $\begin{array}{l}\text { Lateral Diameter } \\
(\mathrm{mm})\end{array}$ & $\begin{array}{l}\text { Fruit Shape } \\
\text { Index }\end{array}$ & $\begin{array}{l}\text { Single fruit } \\
\text { Volume }\left(\mathrm{cm}^{3}\right)\end{array}$ & $\begin{array}{l}\text { Single Fruit } \\
\text { Weight (g) }\end{array}$ \\
\hline Isopyrazam $\cdot$ Azoxystrobin + Chitosan & $83.33 \pm 0.86^{\mathrm{a}}$ & $51.32 \pm 0.48^{\mathrm{a}}$ & $41.08 \pm 0.54^{\mathrm{a}}$ & $1.80 \pm 0.04^{\mathrm{a}}$ & $73.56 \pm 0.96^{a}$ & $102.34 \pm 3.06^{\mathrm{a}}$ \\
\hline Isopyrazam·Azoxystrobin & $82.06 \pm 1.59^{a b}$ & $49.27 \pm 1.01^{b}$ & $40.32 \pm 0.86^{\mathrm{a}}$ & $1.83 \pm 0.06^{\mathrm{a}}$ & $68.25 \pm 2.37^{b}$ & $91.73 \pm 2.27^{b}$ \\
\hline Chitosan & $81.67 \pm 1.96^{\mathrm{ab}}$ & $49.24 \pm 1.63^{b}$ & $40.39 \pm 1.46^{\mathrm{a}}$ & $1.82 \pm 0.07^{\mathrm{a}}$ & $67.94 \pm 0.43^{b}$ & $90.56 \pm 1.18^{b}$ \\
\hline Control & $79.65 \pm 2.47^{b}$ & $48.57 \pm 0.60^{b}$ & $40.26 \pm 0.83^{a}$ & $1.79 \pm 0.08^{\mathrm{a}}$ & $65.18 \pm 1.19^{c}$ & $87.88 \pm 1.10^{b}$ \\
\hline
\end{tabular}

Values indicate the mean \pm SD of three replicates. Different small letters in the same column indicate significant differences at $5 \%$ level $(p<0.05)$.

The effect of isopyrazam·azoxystrobin + chitosan, isopyrazam·azoxystrobin, and chitosan on the quality of kiwifruit fruits is displayed in Table 4. Isopyrazam·azoxystrobin + chitosan, isopyrazam ·azoxystrobin, and chitosan could effectively improve vitamin C, soluble sugar, soluble solid, and dry matter of fruits compared to the control and decrease their titratable acidity. Vitamin C, soluble sugar, soluble solid, and dry matter of kiwifruit fruits treated with isopyrazam azoxystrobin + chitosan were significantly $(p<0.05)$ higher than those of isopyrazam azoxystrobin or chitosan treatments, as well as those of chitosan which were significantly $(p<0.05)$ higher than those of isopyrazam azoxystrobin. These findings demonstrate that chitosan used together with isopyrazam.azoxystrobin could effectively improve kiwifruit fruit quality.

Table 4. The effects of isopyrazam azoxystrobin and chitosan on quality of kiwifruit fruits.

\begin{tabular}{|c|c|c|c|c|c|}
\hline Treatments & Vitamin C $\left(\mathrm{g} \mathrm{kg}^{-1}\right)$ & $\begin{array}{l}\text { Total Soluble } \\
\text { Sugar }(\%)\end{array}$ & Soluble Solid (\%) & Dry Matter (\%) & $\begin{array}{c}\text { Titratable } \\
\text { Acidity (\%) }\end{array}$ \\
\hline Isopyrazam $\cdot$ Azoxystrobin + Chitosan & $1.95 \pm 0.03^{\mathrm{a}}$ & $12.84 \pm 0.06^{\mathrm{a}}$ & $15.80 \pm 0.10^{\mathrm{a}}$ & $19.77 \pm 0.16^{\mathrm{a}}$ & $1.03 \pm 0.03^{c}$ \\
\hline Isopyrazam·Azoxystrobin & $1.86 \pm 0.01^{c}$ & $12.42 \pm 0.03^{c}$ & $15.17 \pm 0.12^{c}$ & $19.14 \pm 0.10^{c}$ & $1.10 \pm 0.04^{b}$ \\
\hline Chitosan & $1.90 \pm 0.02^{b}$ & $12.65 \pm 0.05^{b}$ & $15.43 \pm 0.06^{b}$ & $19.46 \pm 0.01^{b}$ & $1.07 \pm 0.01 \mathrm{bc}$ \\
\hline Control & $1.83 \pm 0.01^{\mathrm{c}}$ & $12.11 \pm 0.06^{\mathrm{d}}$ & $14.50 \pm 0.10^{\mathrm{d}}$ & $18.49 \pm 0.12^{\mathrm{d}}$ & $1.18 \pm 0.01^{\mathrm{a}}$ \\
\hline
\end{tabular}

Values indicate the mean \pm SD of three replicates. Different small letters in the same column indicate significant differences at $5 \%$ level $(p<0.05)$.

The effect of isopyrazam·azoxystrobin + chitosan, isopyrazam·azoxystrobin, and chitosan on the amino acids of kiwifruit fruits is shown in Table 5. Isopyrazam·azoxystrobin + chitosan, isopyrazam·azoxystrobin, and chitosan could effectively increase the total amino acids of fruits compared to the control. Sweet, flavor, bitter, aromatic, essential, nonessential, and total amino acids of kiwifruit fruits treated by isopyrazam azoxystrobin + chitosan were significantly $(p<0.05)$ higher than those of isopyrazam.azoxystrobin or control treatments. Sweet, flavor, aromatic, essential, nonessential, and total amino acids of kiwifruit fruits treated with chitosan were also significantly $(p<0.05)$ higher than those of isopyrazam-azoxystrobin or control treatments; their bitter amino acids were also significantly $(p<0.05)$ higher than those of the control. Simultaneously, sweet, flavor, bitter, aromatic, essential, nonessential, and total amino acids of kiwifruit fruits treated with isopyrazam-azoxystrobin + chitosan were higher than those of chitosan; their essential and total amino acids were significantly $(p<0.05)$ higher than those of chitosan. These findings demonstrate that the promoting effects of fruit amino acids by isopyrazam azoxystrobin + chitosan were superior to those of isopyrazam-azoxystrobin or chitosan alone. 
Table 5. The effects of isopyrazam azoxystrobin and chitosan on amino acids of kiwifruit fruits.

\begin{tabular}{|c|c|c|c|c|}
\hline Amino Acids ( $\left.\mathrm{g} \mathrm{kg}^{-1}\right)$ & Isopyrazam $\cdot$ Azoxystrobin + Chitosan & Isopyrazam·Azoxystrobin & Chitosan & Control \\
\hline Aspartic & 0.87 & 0.83 & 0.86 & 0.84 \\
\hline Glutamate & 1.84 & 1.82 & 1.83 & 1.78 \\
\hline Cystine & 0.97 & 0.94 & 0.95 & 0.96 \\
\hline Serine & 0.78 & 0.76 & 0.75 & 0.74 \\
\hline Glycine & 0.76 & 0.68 & 0.73 & 0.72 \\
\hline Histidine & 0.68 & 0.67 & 0.68 & 0.65 \\
\hline Arginine & 1.41 & 1.37 & 1.39 & 1.34 \\
\hline Threonine & 0.45 & 0.45 & 0.46 & 0.47 \\
\hline Alanine & 0.74 & 0.68 & 0.72 & 0.66 \\
\hline Proline & 1.22 & 1.27 & 1.25 & 1.28 \\
\hline Tyrosine & 0.67 & 0.67 & 0.66 & 0.65 \\
\hline Valine & 0.66 & 0.59 & 0.64 & 0.63 \\
\hline Methionine & 0.57 & 0.58 & 0.55 & 0.56 \\
\hline Isoleucine & 0.61 & 0.57 & 0.58 & 0.54 \\
\hline Leucine & 0.63 & 0.53 & 0.56 & 0.55 \\
\hline Phenylalanine & 0.74 & 0.69 & 0.71 & 0.67 \\
\hline Lysine & 0.92 & 0.85 & 0.88 & 0.87 \\
\hline Sweet amino acids & $4.63 \pm 0.05^{\mathrm{a}}$ & $4.51 \pm 0.07^{\mathrm{b}}$ & $4.59 \pm 0.06^{\mathrm{a}}$ & $4.52 \pm 0.06^{\mathrm{b}}$ \\
\hline Flavor amino acids & $3.63 \pm 0.06^{\mathrm{a}}$ & $3.50 \pm 0.08^{b}$ & $3.57 \pm 0.09^{\mathrm{a}}$ & $3.49 \pm 0.08^{b}$ \\
\hline Bitter amino acids & $3.88 \pm 0.08^{a}$ & $3.64 \pm 0.07^{b}$ & $3.72 \pm 0.08^{a b}$ & $3.62 \pm 0.05^{c}$ \\
\hline Aromatic amino acids & $2.38 \pm 0.05^{\mathrm{a}}$ & $2.30 \pm 0.06^{b}$ & $2.32 \pm 0.07^{\mathrm{a}}$ & $2.28 \pm 0.08^{b}$ \\
\hline Essential amino acids & $4.58 \pm 0.06^{\mathrm{a}}$ & $4.26 \pm 0.07^{\mathrm{c}}$ & $4.38 \pm 0.06^{b}$ & $4.29 \pm 0.04^{c}$ \\
\hline Nonessential amino acids & $8.72 \pm 0.07^{\mathrm{a}}$ & $8.42 \pm 0.08^{b}$ & $8.57 \pm 0.09^{a}$ & $8.34 \pm 0.08^{b}$ \\
\hline Total amino acids & $14.52 \pm 0.11^{\mathrm{a}}$ & $13.95 \pm 0.11^{\mathrm{c}}$ & $14.20 \pm 0.09^{b}$ & $13.91 \pm 0.12^{c}$ \\
\hline
\end{tabular}

Values indicate the mean \pm SD of three replicates. Different small letters in the same line indicate significant differences at $5 \%$ level $(p<0.05)$.

\section{Discussion}

Isopyrazam is a succinate dehydrogenase inhibitor fungicide that has outstanding bioactivity against Sphaerotheca fuliginea, Sclerotinia sclerotiorum, Puccinia striiformis, Botrytis cinerea, Ascochyta graminicola, etc. [29-32]. Azoxystrobin belongs to the group of mitochondrial respiration inhibitor fungicides and possesses broad-spectrum systemic activity against the four major classes of pathogenic fungi [33-35]. Chitosan has antifungal activity against various fungal pathogens [16-18]. The results here show that $29 \%$ isopyrazam azoxystrobin SC had excellent toxic activity against $L$. theobromae with an $\mathrm{EC}_{50}$ value of $0.1826 \mathrm{mg} \mathrm{kg}^{-1}$, and chitosan possessed a relatively inferior toxicity against L. theobromae. This work extends the antimicrobial spectrum of isopyrazam.azoxystrobin and chitosan. Moreover, foliar application of $29 \%$ isopyrazam azoxystrobin SC 1500-time + chitosan 100-time liquid against leaf spot disease had a field control efficacy of $86.83 \%$, which was significantly $(p<0.05)$ higher than $78.70 \%$ of $29 \%$ isopyrazam azoxystrobin SC 1000-time liquid and significantly $(p<0.01)$ better than $55.33 \%$ of chitosan 100 -time liquid. This suggests that isopyrazam azoxystrobin and chitosan had a notably synergetic effect for controlling leaf spot disease of kiwifruit, and their co-application could effectively reduce isopyrazam azoxystrobin application. Isopyrazam is an active ingredient with both preventive and therapeutic properties, and azoxystrobin is one of the leading worldwide proprietary fungicides with preventive, therapeutic, eradicant, translaminar, and systemic properties [36,37]. Chitosan can activate plant defense responses via inducing various defense-related reactions $[16-18,22,23]$. The effective control effect of isopyrazam azoxystrobin + chitosan on leaf spot disease was probably derived from the excellent preventive and therapeutic properties of isopyrazam-azoxystrobin, as well as the superior induced resistance effect of chitosan.

Soluble proteins include many related proteins that induce plant disease defense, and MDA is an indicator of membrane lipid peroxidation, as well as CAT, POD, PPO, and SOD which are defense enzymes closely related to plant disease resistance [38,39]. A variety of reports have also indicated that chitosan could induce an increase in proteins, decrease MDA, and boost defense enzyme activity, thereby enhancing plant disease resistance $[16-18,22,23,38-42]$. The present results show that compared to isopyrazam azoxystrobin, chitosan, or control, isopyrazam azoxystrobin + chitosan significantly $(p<0.01)$ enhanced soluble protein, CAT, POD, PPO, and SOD activities of kiwifruit leaves and decreased their MDA content. Simultaneously, chitosan could significantly $(p<0.05)$ improve soluble 
protein, CAT, and SOD activities of kiwifruit leaves compared to isopyrazam azoxystrobin. Our previous results also indicate that chitosan could significantly $(p<0.05)$ improve the promoting effects of tetramycin on total phenolics, total flavonoids, SOD activity of kiwifruit, and enhance the disease resistance of kiwifruit. These results emphasize that the co-application of isopyrazam-azoxystrobin and chitosan could effectively improve the enhancing or inhibiting effects of isopyrazam azoxystrobin or chitosan on the soluble protein, MDA, CAT, POD, PPO, and SOD activities of kiwifruit leaves, which are more helpful for improving the disease resistance of kiwifruit.

Photosynthesis is the physiological basis of plant growth and development, and its essential pigment is chlorophyll. Transpiration is the main driving force for plants to absorb and transport water and nutrients. Chitosan can enhance plant growth and development by promoting the photosynthetic rate by increasing the chlorophyll content $[18,22]$. The results of this work show that the co-application of isopyrazam-azoxystrobin and chitosan effectively increased the chlorophyll, photosynthetic rate, transpiration rate, and water use efficiency of kiwifruit compared with isopyrazam azoxystrobin, chitosan, or control. This favorable effect could result from the closely synergistic effect between isopyrazam azoxystrobin on protecting plant leaf organs from pathogens and chitosan on promoting plant growth. The adequate growth and development of kiwifruit determine its fruit yield and quality. Dzung et al. [43] reported that chitosan can promote plant growth by triggering the cytokinin and auxin of signal transduction and gene expression, as well as increasing nutrient intake. Our previous study also showed that the foliar application of chitosan or chitosan + tetramycin notably improved the growth, quality, and aroma of kiwifruit fruits [25]. The current results demonstrate that the promoting effects of isopyrazam azoxystrobin + chitosan on the growth and quality of kiwifruit fruits were better than those of isopyrazam-azoxystrobin or chitosan alone. This is closely related to their division of labor: isopyrazam-azoxystrobin can protect kiwifruit from pathogen infection and chitosan can induce its disease resistance and promote its healthy growth.

The closer the amino acid composition of foods is to that of human protein, the higher its nutritional value. According to the amino acid model of protein nutritional value proposed by the World Health Organization (WHO) and the Food and Agriculture Organization of United Nations (FAO), it is considered that essential amino acids with superior quality account for about $40 \%$ of the total amino acids, and the ratio of essential amino acids to nonessential amino acids is more than 0.6 [44]. In this study, the percentage of essential amino acids in total amino acids and the ratio of essential amino acids to nonessential amino acids in kiwifruit fruits treated by isopyrazam azoxystrobin + chitosan, isopyrazam azoxystrobin, chitosan, and control were $31.54 \%$ and $0.53,30.54 \%$ and 0.51 , $30.85 \%$ and 0.51 , as well as $30.84 \%$ and 0.51 , respectively. These results illustrate that the protein nutritional value of kiwifruit fruits treated with isopyrazam azoxystrobin + chitosan was more closer to the ideal mode value than other treatments, highlighting that chitosan is an effective adjuvant of isopyrazam-azoxystrobin that enhances its improvement for kiwifruit amino acids.

At present, the reducing application of chemical fungicides has been welcomed and recognized by the public. Furthermore, increasing attention has been focused on natural products with high efficacy, nontoxic, and low risk as adjuvants of chemical fungicides to more effectively control plant diseases and decrease chemical fungicide application [45]. In this work, the co-application of isopyrazam-azoxystrobin and chitosan effectively enhanced the resistance of kiwifruit against leaf spot disease and notably enhanced its photosynthesis, growth, and quality, as well as reliably reduced isopyrazam.azoxystrobin application. Chitosan is a natural nontoxic substance widely used in food, medicine, cosmetics, and other fields. Additionally, the field concentration of $29 \%$ isopyrazam azoxystrobin SC (1500-time dilution liquid) was relatively low, and the safe interval (25 July to 25 September, 62 days) and soft ripening (more than 20 days) periods of kiwifruit were also very long. Therefore, the potential food safety risk caused by isopyrazam azoxystrobin + chitosan is almost nonexistent. Moreover, since $L$. theobromae was also reported as a post-harvest fungal 
disease, whether isopyrazam-azoxystrobin + chitosan will also affect the preservation of kiwifruit, as well as the residue analysis of isopyrazam-azoxystrobin in fruits and its safety evaluation will be topics for future research. This work highlights that the co-application of isopyrazam·azoxystrobin and chitosan can be used as a green, safe, and efficient approach for controlling leaf spot disease of kiwifruit, and enhancing its resistance, growth, and quality, as well as decreasing the application of chemical fungicides.

\section{Conclusions}

In conclusion, chitosan could effectively assist isopyrazam·azoxystrobin against leaf spot disease of kiwifruit. The co-application of isopyrazam-azoxystrobin and chitosan notably enhanced soluble protein, CAT, POD, PPO, and SOD activities in kiwifruit leaves and reduced their MDA content, as well as reliably improved the chlorophyll, photosynthetic rate, transpiration rate, and water use efficiency of kiwifruit. Additionally, the co-application of isopyrazam-azoxystrobin and chitosan was more effective than isopyrazam azoxystrobin or chitosan alone in promoting the growth, quality, and amino acids of kiwifruit fruits. This work highlights that the co-application of isopyrazam-azoxystrobin and chitosan can be used as a promising agricultural practice for controlling leaf spot disease of kiwifruit.

Author Contributions: Y.L. (Youhua Long) constructed the project; Y.L. (Youhua Long), Y.S. and Q.W. designed the experiments; Q.W. and H.L. performed the experiments; Q.W. and Y.L. (Yang Lei) analyzed the data; Q.W. wrote the paper. All authors have read and agreed to the published version of the manuscript.

Funding: This work was supported by China Agriculture Research System of MOF and MARA, the Science and technology innovation talent project of Guizhou Province [No. (2016)5672], the Support Plan Projects of Science and Technology Department of Guizhou Province (No. (2021) YB237, (2020)1Y016, (2019)2703, (2017)2566-1), the Support Plan Projects of Guiyang City (No. (2017)26-1).

Institutional Review Board Statement: Not applicable.

Informed Consent Statement: Not applicable.

Data Availability Statement: The datasets during or analyzed during the current study available from the corresponding author on reasonable request.

Conflicts of Interest: We declare that we do not have any commercial or associative interest that represents a conflict of interest in connection with the work submitted.

\section{References}

1. Hu, H.; Zhou, H.; Li, P. Lacquer wax coating improves the sensory and quality attributes of kiwifruit during ambient storage. Sci. Hortic. 2019, 244, 31-41. [CrossRef]

2. Wang, Q.; Zhang, C.; Li, J.; Wu, X.; Long, Y.; Su, Y. Intercropping Vicia sativa L. Improves the Moisture, Microbial Community, Enzyme Activity and Nutrient in Rhizosphere Soils of Young Kiwifruit Plants and Enhances Plant Growth. Horticulturae 2021, 7, 335. [CrossRef]

3. Wang, Q.; Zhang, C.; Long, Y.; Wu, X.; Su, Y.; Lei, Y.; Ai, Q. Bioactivity and Control Efficacy of the Novel Antibiotic Tetramycin against Various Kiwifruit Diseases. Antibiotics 2021, 10, 289. [CrossRef] [PubMed]

4. Zhao, J.M.; Gao, G.T.; Gu, L.J.; Sun, X.Y.; Xue, X.Y.; Geng, P.F.; Lei, Y.S. Identification and Pharmaceutical Screening of Brown Spot Disease on Actinidia chinensis. Sci. Agric. Sin. 2013, 46, 4916-4925. [CrossRef]

5. Yuan, G.Q.; Xie, Y.L.; Tan, D.C.; Li, Q.Q.; Lin, W. First Report of Leaf Spot Caused by Corynespora cassiicola on Kiwifruit (Actinidia chinensis) in China. Plant Dis. 2014, 98, 1586. [CrossRef]

6. Kikuhara, K.; Nakashima, C. Sooty spot of kiwifruit caused by Pseudocercospora actinidiae Deighton. J. Gen. Plant Pathol. 2008, 74, 185-187. [CrossRef]

7. Jeong, I.-H.; Lim, M.-T.; Kim, G.-H.; Han, T.-W.; Kim, H.-C.; Kim, M.-J.; Park, H.-S.; Shin, S.-H.; Hur, J.-S.; Shin, J.-S.; et al. Incidences of Leaf Spots and Blights on Kiwifruit in Korea. Plant Pathol. J. 2008, 24, 125-130. [CrossRef]

8. Shi, J.Q.; Zhang, R.Q.; Long, Y.H.; Hu, A.L.; Mo, F.X.; Li, W.Z. Identification and Biological Characteristics of a Kiwifruit Leaf Spot Disease Pathogen. North Hortic. 2021, 12, 44-49.

9. Naseri, B. Legume Root Rot Control Through Soil Management for Sustainable Agriculture. In Sustainable Management of Soil and Environment; Springer: Berlin/Heidelberg, Germany, 2019; pp. 217-258. 
10. Cameron, A.; Sarojini, V. Pseudomonas syringaepv.actinidiae: Chemical control, resistance mechanisms and possible alternatives. Plant Pathol. 2013, 63, 1-11. [CrossRef]

11. Wicaksono, W.A.; Jones, E.E.; Casonato, S.; Monk, J.; Ridgway, H.J. Biological control of Pseudomonas syringae pv. actinidiae (Psa), the causal agent of bacterial canker of kiwifruit, using endophytic bacteria recovered from a medicinal plant. Biol. Control 2018, 116, 103-112. [CrossRef]

12. Slusarenko, A.J.; Patel, A.; Portz, D. Control of plant diseases by natural products: Allicin from garlic as a case study. Eur. J. Plant Pathol. 2008, 121, 313-322. [CrossRef]

13. Borlinghaus, J.; Albrecht, F.; Gruhlke, M.C.H.; Nwachukwu, I.; Slusarenko, A.J. Allicin: Chemistry and Biological Properties. Molecules 2014, 19, 12591-12618. [CrossRef] [PubMed]

14. Naseri, B. Epidemics of Rhizoctonia Root Rot in Association with Biological and Physicochemical Properties of Field Soil in Bean Crops. J. Phytopathol. 2013, 161, 397-404. [CrossRef]

15. Naseri, B. Bean production and fusarium root rot in diverse soil environments in Iran. J. Soil Sci. Plant Nutr. 2014, 14, 177-188. [CrossRef]

16. Verlee, A.; Mincke, S.; Stevens, C.V. Recent developments in antibacterial and antifungal chitosan and its derivatives. Carbohydr. Polym. 2017, 164, 268-283. [CrossRef]

17. Chakraborty, M.; Hasanuzzaman, M.; Rahman, M.; Khan, A.R.; Bhowmik, P.; Mahmud, N.U.; Tanveer, M.; Islam, T. Mechanism of Plant Growth Promotion and Disease Suppression by Chitosan Biopolymer. Agriculture 2020, 10, 624. [CrossRef]

18. Torres-Rodriguez, J.A.; Reyes-Pérez, J.J.; Castellanos, T.; Angulo, C.; Quiñones-Aguilar, E.E.; Hernandez-Montiel, L.G. A biopolymer with antimicrobial properties and plant resistance inducer against phytopathogens: Chitosan. Not. Bot. Horti Agrobot. Cluj-Napoca 2021, 49, 12231. [CrossRef]

19. Rahman, M.; Mukta, J.A.; Sabir, A.A.; Gupta, D.R.; Mohi-Ud-Din, M.; Hasanuzzaman, M.; Miah, M.G.; Rahman, M.; Islam, M.T. Chitosan biopolymer promotes yield and stimulates accumulation of antioxidants in strawberry fruit. PLoS ONE 2018, 13, e0203769. [CrossRef]

20. Coutinho, T.C.; Ferreira, M.C.; Rosa, L.H.; de Oliveira, A.M.; Júnior, E.N.D.O. Penicillium citrinum and Penicillium mallochii: New phytopathogens of orange fruit and their control using chitosan. Carbohydr. Polym. 2020, 234, 115918. [CrossRef]

21. El Amerany, F.; Meddich, A.; Wahbi, S.; Porzel, A.; Taourirte, M.; Rhazi, M.; Hause, B. Foliar Application of Chitosan Increases Tomato Growth and Influences Mycorrhization and Expression of Endochitinase-Encoding Genes. Int. J. Mol. Sci. 2020, 21, 535. [CrossRef]

22. Li, J.; Guo, Z.; Luo, Y.; Wu, X.; An, H. Chitosan Can Induce Rosa roxburghii Tratt. against Sphaerotheca sp. and Enhance Its Resistance, Photosynthesis, Yield, and Quality. Horticulturae 2021, 7, 289. [CrossRef]

23. Berger, L.R.R.; Stamford, N.P.; Willadino, L.G.; Laranjeira, D.; de Lima, M.A.B.; Malheiros, S.M.M.; de Oliveira, W.J.; Stamford, T.C.M. Cowpea resistance induced against Fusarium oxysporum f. sp. tracheiphilum by crustaceous chitosan and by biomass and chitosan obtained from Cunninghamella elegans. Biol. Control. 2016, 92, 45-54. [CrossRef]

24. Obianom, C.; Romanazzi, G.; Sivakumar, D. Effects of chitosan treatment on avocado postharvest diseases and expression of phenylalanine ammonia-lyase, chitinase and lipoxygenase genes. Postharvest Biol. Technol. 2019, 147, 214-221. [CrossRef]

25. Wang, Q.; Zhang, C.; Wu, X.; Long, Y.; Su, Y. Chitosan Augments Tetramycin against Soft Rot in Kiwifruit and Enhances Its Improvement for Kiwifruit Growth, Quality and Aroma. Biomolecules 2021, 11, 1257. [CrossRef]

26. Zhang, C.; Long, Y.-H.; Wang, Q.-P.; Li, J.-H.; Wu, X.-M.; Li, M. The Effect of Preharvest 28.6\% Chitosan Composite Film Sprays for Controlling Soft Rot on Kiwifruit and Its Defense Responses. Hortic. Sci. 2019, 46, 180-194. [CrossRef]

27. Zhang, C.; Long, Y.; Li, J.; Li, M.; Xing, D.; An, H.; Wu, X.; Wu, Y. A Chitosan Composite Film Sprayed before Pathogen Infection Effectively Controls Postharvest Soft Rot in Kiwifruit. Agronomy 2020, 10, 265. [CrossRef]

28. Zhang, C.; Wang, Q.P.; Wu, X.M.; Long, Y.H.; Wu, Y.Y.; Huang, Y.X.; Tang, J.W. Effects of Forchlorfenuron on Amino Acids and Aroma Components of Guichang Kiwifruit Postharvests. J. Nucl. Agric. Sci. 2019, 33, 2186-2194. [CrossRef]

29. Harp, T.L.; Godwin, J.R.; Scalliet, G.; Walter, H.; Stalker, A.D.; Bartlett, D.W.; Ranner, D.J. Isopyrazam, a New Generation Cereal Fungicide. Asp. Appl. Biol. 2011, 106, 113-120.

30. Song, Y.; Zhang, Z.; Chen, L.; He, L.; Lu, H.; Ren, Y.; Mu, W.; Liu, F. Baseline Sensitivity of Botrytis cinerea to the Succinate Dehydrogenase Inhibitor Isopyrazam and Efficacy of this Fungicide. Plant Dis. 2016, 100, 1314-1320. [CrossRef]

31. He, L.-M.; Cui, K.-D.; Ma, D.-C.; Shen, R.-P.; Huang, X.-P.; Jiang, J.-G.; Mu, W.; Liu, F. Activity, Translocation, and Persistence of Isopyrazam for Controlling Cucumber Powdery Mildew. Plant Dis. 2017, 101, 1139-1144. [CrossRef]

32. Huang, X.-P.; Song, Y.-F.; Li, B.-X.; Mu, W.; Liu, F. Baseline sensitivity of isopyrazam against Sclerotinia sclerotiorum and its efficacy for the control of Sclerotinia stem rot in vegetables. Crop Prot. 2019, 122, 42-48. [CrossRef]

33. Adetutu, E.; Ball, A.; Osborn, A. Azoxystrobin and soil interactions: Degradation and impact on soil bacterial and fungal communities. J. Appl. Microbiol. 2008, 105, 1777-1790. [CrossRef] [PubMed]

34. Rodrigues, E.T.; Lopes, I.; Pardal, M.Â. Occurrence, fate and effects of azoxystrobin in aquatic ecosystems: A review. Environ. Int. 2013, 53, 18-28. [CrossRef] [PubMed]

35. Wang, H.; Huang, Y.; Wang, J.; Chen, X.; Wei, K.; Wang, M.; Shang, S. Activities of azoxystrobin and difenoconazole against Alternaria alternata and their control efficacy. Crop Prot. 2016, 90, 54-58. [CrossRef] 
36. Dubos, T.; Pasquali, M.; Pogoda, F.; Casanova, A.; Hoffmann, L.; Beyer, M. Differences between the succinate dehydrogenase sequences of isopyrazam sensitive Zymoseptoria tritici and insensitive Fusarium graminearum strains. Pestic. Biochem. Physiol. 2013, 105, 28-35. [CrossRef] [PubMed]

37. Marczewska, P.; Płonka, M.; Rolnik, J.; Sajewicz, M. Determination of azoxystrobin and its impurity in pesticide formulations by liquid chromatography. J. Environ. Sci. Heal. Part B 2020, 55, 599-603. [CrossRef] [PubMed]

38. Vlot, A.C.; Sales, J.H.; Lenk, M.; Bauer, K.; Brambilla, A.; Sommer, A.; Chen, Y.; Wenig, M.; Nayem, S. Systemic propagation of immunity in plants. New Phytol. 2021, 229, 1234-1250. [CrossRef]

39. Lopez-Moya, F.; Suarez-Fernandez, M.; Lopez-Llorca, L.V. Molecular Mechanisms of Chitosan Interactions with Fungi and Plants. Int. J. Mol. Sci. 2019, 20, 332. [CrossRef]

40. El-Mohamedya, R.S.R.; Abd El-Aziz, M.E.; Kamel, S. Antifungal Activity of Chitosan Nanoparticles against Some Plant Pathogenic Fungi In Vitro. Agric. Eng. Int. CIGR J. 2019, 21, 201-209.

41. Yan, J.; Cao, J.; Jiang, W.; Zhao, Y. Effects of preharvest oligochitosan sprays on postharvest fungal diseases, storage quality, and defense responses in jujube (Zizyphus jujuba Mill. cv. Dongzao) fruit. Sci. Hortic. 2012, 142, 196-204. [CrossRef]

42. Ma, Z.; Yang, L.; Yan, H.; Kennedy, J.F.; Meng, X. Chitosan and oligochitosan enhance the resistance of peach fruit to brown rot. Carbohydr. Polym. 2013, 94, 272-277. [CrossRef] [PubMed]

43. Dzung, N.A.; Khanh, V.T.P.; Dzung, T.T. Research on impact of chitosan oligomers on biophysical characteristics, growth, development and drought resistance of coffee. Carbohydr. Polym. 2011, 84, 751-755. [CrossRef]

44. Zhu, S.T.; Wu, K. Nutritional evaluation of protein-Ratio coefficient of amino acid. Acta Nutr. Sin. 1988, 10, 187-190.

45. Newman, D.J.; Cragg, G.M. Natural Products As Sources of New Drugs over the 30 Years from 1981 to 2010. J. Nat. Prod. 2012, 75, 311-335. [CrossRef] [PubMed] 